\title{
La Conspiración de González, Cabero y Anzules.
}

Es evidentemente paradojal que en la etapa más agitada de nuestra vida republicana o seadurante la llamada Anarquía Militar, que abarca desde la muerte del Presidente Gamarra en el campo de Ingavi, el 18 de Noviembre de I84I, hasta la ascensión por primera vez al poder de don Ramón Castilla, el 20 de Abril de I845, haya existido un momento en que se creyó que la paz pública se había afianzado con una solidez pocas veces conocicta en nuestra convulsionada patria en el siglo anterior.

"Ello ocurrió en Abril de I843, cuando se inaugura en Lima el régimen Directorial, ya proclamado en el Sur dos meses antes, a raíz de la entrada jubilosa a esta ciudad del General Manuel Ignacio de Vivanco, el día 7 del mes y año expresados.

En efecto, ningún gobierno se instauró en nuestro país, por aquella época, bajo más benévolos auspicios e, igualmente, pocos personajes políticos han llegado a la primera magistratura del Estado aureolados de mayor prestigio que el Regenerador en I843.

Sabido es que Vivanco, a la desaparición de Salaverry, fué escogido por el núcleo más importante de los amigos de este general como su sucesor en la politica peruana y que 
en Chile se formó, en 1836 , entre nuestros compatriotas emigrados, una influyente, aunque reducida camarilla, llamada por los demás exilados la zabandija palaciega, que trató de conseguir que el gobierno de La Moneda lo colocase al frente de los elementos nacionales en la expedición destinada a combatir a Santa Cruz y la Confederación.

Vivanco, que tenía en aquel año solamente el grado de Coronel y era apenas unos meses mayor que Salaverry, fué considerado entonces por sus partidarios con tanta energía como este último, al mismo tiempo que sereno y reflexivo, así como dotado de mayor inteligencia y, lo que si era cierto, más ilustrado que el vencido de Socabaya.

El asesinato de Portales, por una parte, así como la presencia de La Fuente y, poco más tarde, la decisiva aparición en Chile de Gamarra, frustraron en esa oportunidad el encumbramiento del nuevo caudillo.

Triunfante la Restauración, ya Gamarra en la presidencia, encontrándose Vivanco de prefecto en Arequipa, se produjo a su favor, en esa ciudad, en Enero de I84I, la revolución denominadalporesus autorestaela Regeneración Nacional, que, como es conocidb, tuvoeum formidable éxito en su iniciación, pero que a los tres meses era deshecha por Castilla.

El general revolucionario, sentenciado a muerte, se refugió en Bolivia y allí se encontraba el día de Ingavi. Inmediatamente regresó al Perú por la frontera de Tacna, haciendo protestas de su intención de ponerse al servicio del gobierno legítimo y radicándose en Arequipa, donde fué acogido con extraordinaria alegría, a pesar de su fracaso en la intentona regeneradora.

Cuando al firmarse el tratado de paz Perú-boliviano, en Acora, el 7 de Junio de I842, vuelve a encenderse la discordia civil en nuestro suelo, Vivanco se plega a la causa de Vidal y La Fuente, pero, dejando ya vislumbrar sus futuros planes, no se desprende de las tropas bajo su mando y 
se mantiene como el verdadero amo de Arequipa. Al establecerse en Lima, después de Agua Santa, el gobierno del 2." Vice-presidente del Consejo de Estado, General don Francisco de Vidal, no se modificó la situación con respecto al nombrado caudillo y la ciudad que controlaba y le era adicta.

A mediados de Noviembre de I842, emprendió Vivanco la pacificación de Puno y Cusco, levantados contra el nuevo gobierno, convirtiéndose su marcha militar en un verdadero paseo triunfal, pues, en veinte días, sin derramar una gota de sangre ni disparar un tiro, normalizó la situación en esos dos departamentos, se concitó favorablemente los sentimientos de sus habitantes y de esta manera, a fines de I842, tenía de hecho en sus manos todo el Sur de la República.

Resultaba, pues, una seria amenaza para la estabilidad del régimen de Viclal y, sobre todo, para los planes presidenciales de La Fuente, A fin de alejarlo de la escena política se le ofreció la plenipotencia en Bolivia y como no la aceptase, en un arrancute de asadía, el gobierno de Lima lo nombró Ministro de Guerra. Todo hace creer que Vivanco admitió sinceramente là cartera, cuando, hallándose en el Cusco, recibió la noticia de su designación, pero ya era demasiado tarde, pues, simultáneamente, sus allegados y amigos habían sublevado la Ciudad Mistiana a su favor en la noche del 28 de Enero de I843.

La rebelión, según se ha asegurado, fué encabezada por la propia esposa del caudillo, doña Cipriana La Torre y Luna Pizarro de Vivanco, que, imitando los ímpetus heroicos de su contemporánea la Mariscala, se presentó en el cuartel del batallón de "Cazadores del Ejército", arengó a los soldados y dió la señal para la iniciación del movimiento, que se propagó inmediatamente a los demás cuerpos acantonados en la población. .El pueblo arequipeño, ferviente admirador de Vivanco, tomó parte activa en los aconte- 
cimientos y, sobre todo, en el apresamiento del Prefecto Deustua y del jefe de las tropas Mariscal Nieto.

Vivanco, dejándose arrastrar, al parecer, por los hechos consumados, aprobó la sublevación realizada en su nombre. El 3 de Febrero, proclamó, desde el Cusco, que astmía el mando de la nación y, el 20 del mismo mes, en Lampa, tomó el título de Director Supremo, que continuó usando mientras ejerció el poder y que ha dado nombre a su gobierno.

El contagio revolucionario se extendió en menos de dos meses por todo el país. Puno se pronunció a mediados de Febrero y un mes después se unían a la causa vivanquista, en el valle de Jauja, las fuerzas enviadas de Lima para combatirlo y que eran el único sostén del gobierno de Vidal. Este resignó el mando el 15 de Marzo y, tras el brevísimo paso por el Palacio de los Virreyes de don Justo Figuerola, el verdadero gobernante legítimo, la revolución del Coronel Arámburu, en los cuarteles de la capital, abrió las puertas de esta ciudad al afortunado caudillo del Sur.

\section{Biblioteca de Letras}

\section{"Jorge Puccinelli Converso"}

Ya hemos dicho que en ese instante histórico la posición política de Vivanco era inmejorable. Su autoridad había sido reconocida en todo el territorio nacional. Contaba con la adhesión de la movida región del Sur y, en especial, con la de Arequipa, ẹl mayor foco revolucionario. En Lima, tenía predispuestos en su favor todos los sectores de la opinión. Como hechura de un grupo de intelectuales pertenecientes a los más altos círculos, fué el ídolo de la aristocracia; hombre de orden, recibió el más franco apoyó de los comerciantes, las personas adineradas y la clase media; limeño, de figura atrayente, amante de presentarse en público, lo aclamó la simpatía poptlar. 
El momento político, además, era muy favorable para las ideas conservadoras y autoritarias que encarnaba el Regenerador. El liberalismo de los albores de la República ya no existia, más aún después del fracaso de la causa de Torrico, que tuvo un ligero matiz de esta índole principista. Vidaurre había fallecido tres años antes creyendo haber abdicado de su pensamiento libre ante la fé y la tradición; Luna Pizarro, tío de la esposa de Vivanco, presentado poco después por éste para el arzobispado, se encontraba convertido, ya en la última fase de su vida, al credo conservador; Francisco Javier Mariátegui había aceptadó del joven caudillo una vocalía en la Corte Suprema; Pérez de Tudela era presidente de la misma corporación; Vigil, en Tacna, despreocupado de la política activa, se entregaba a su obra enorme sobre la defensa de los gobiernos ante la Curia Romana. Solamente Lazo, espécimen raro de político que con la edad se pasa del conservadorismo a las filas liberales, podía haber adoptado una postura contraria a la tendencia vivanquista, pero, habiendo sido ministro de la facción derrocada de La Fuente, no estaba en aptitud para ello. En cuanto a la nueva generación liberal, aún no había eclosionado. Pedro Gálvez estudiaba con distinción en San Carlos, su hermano José era un niño, como Felipe Alvarado y Fernando Casós.

En cambio, los conservadores y autoritaristas estaban en todo su apogeo. Andrés Martínez, partidario del militarismo a la manera de José María de Pando, ejercía un decisivo influjo en Arequipa y era colaborador leal hasta el sacrificio del Supremo Director; Felipe Pardo, recién amagado por su terrible mal, aparecía como la lumbrera de los poderosos círculos sociales capitalinos y Bartolomé Herrera, ya famoso por su tremenda y oportuna catilinaria en las exeqtiias de Gamarra, así como por su labor didáctica en San Carlos, se manifestaba como el campeón del reaccionaris- 
mo y, aunque nombrado al mencionado instituto por Vidal, no podía ser adverso al nuevo gobernante, que encarnaba sus aspiraciones doctrinarias.

Era también Vivanco en ese tiempo el más importante de los caudillos militares. Gamarra había muerto en el campo de batalla; Santa Cruz estaba desprestigiado por sus derrotas; Castilla, que intentó en vano sostener el gobierno legal de Figuerola, se retiró desengañado al fundo "El Pino"; Orbegoso vivía en el destierro y sin opción política alguna; Vidal y La Fuente, recientemente desposeídos del mando, se hallaban desopinados, sobre todo el segundo; Torrico y San Román, desacreditados, a su vez, se encontraban en Bolivia después de su derrota en Agua Santa; Nieto, enfermo, tenía su reputación menoscabada por haber sostenido al régimen derrocado; Bermúdez se veía en igual condición como presidente del Congreso que pretendió reunir La Fuente; Echenique, Pezet, Deustua, sin ambiente popular todavía, eran, los dos primeros, adictos a Vivanco y el último, apresado en Arequipa durante la revolución del 28 de Enero, holestaba end condicionessde inspirar serio temor al astro político del día.lli Converso"

Sin embargo, esta situación de indiscutida preponderancia poco duró al joven triunfador. No puede decirse que su administración se iniciase desacertadamente en cuanto a la gestión de los negocios públicos se refiere. Vivanco, inteligente, culto, laborioso, bien intencionado, trató indudablemente de realizar útiles y necesarias reformas. Manejó la hacienda nacional con probidad y economía, pretendió llevar a caho la reducción del ejército, regularizar un escalafón militar excesivo, expurgar las listas pasivas, impulsar la instrucción, hacer un presupuesto, mejorar la justicia, realizar obras putblicas, pero, con un ilimitado empeño de autoridad, implantó la más rígida dictadura y pronto dió a conocer algunas facetas, hasta entonces ignoradas, de su 
personalidad. Se manifestó autocrático, intransigente, despiadado, ingrato $\mathrm{y}$, más què nada, exageradamente vano. Demostró, también, que carecía de sentido político. Postergó la reunión del Congreso, cuyo funcionamiento anhelaban los pueblos después de las últimas guerras civiles; abolió la Constitución de Huancayo, sin acogerse a ninguna otra y exigió de los funcionarios civiles, militares y eclesiásticos un juramento antidemocrático de obediencia a su persona, que fué la causa principal para que se precipitasen a la rebelión los más destacados jefes del ejército de la época. Además, le faltó tino en lo que respecta a la puesta en práctica de ciertas medidas, como las reducciones en la fuerza armada, que pretendió llevarlas a cabo drásticamente, separando de las filas a centenares de oficiales, que al verse en la miseria comenzaron a actuar enérgicamente contra su gobierno.

De esta manera, si escasos regímenes políticos, como llevamos dicho, se inauguraron con más fuerza y prestigio, muy pocos, igualmente, fueron más combatidos desde el primer instante. Alprincipinsa deeMayordes I843, apenas trascurrido un mesode su triunfal entrada a Lima, ya tenía que defenderse de la abierta beligerancia de los más importantes candillos militares del país. Torrico y San Román, apoyados por Ballivián, desagradado con Vivanco por varios motivos, se aprestaban a invadir Puno, como lo efectuaron a fines del mismo Mayo. Castilla había fugado de la capital en los íltimos días de Abril y, a principios del mes siguiente, se apoderaba de la provincia de Tarapacá. Nieto, Bermúdez, Mendiburu y Cisneros, al marchar al destierro, que les impuso Vivanco, desembarcaron en Arica y revolucionaron Tacna. Lizarzaburu, en el Norte, se negaba a prestar el juramento al Director y, en Lima, los amigos de Vidal, deportado a Chile el 2 de Mayo de I843, de La Fuente, que también había sido exilado a ese país y de Deustua, cuyo pensamiento era una incógnita para el gobierno direc- 
torial, comenzaron a conspirar e intrigar con una actividad hija del hambre y la desesperación.

Estos complots se multiplicaron mientras Vivanco ejerció el mando en Lima, es decir del 7 de Abril al 30 de Noviembre de 1843 . De ellos, tres nos son más conocidos por los procesos a que dieron lugar: el de Gonzalez, el de la señora de Nieto y el de Lastres y Verástegui o de las Sortijas Negras, como lo ha llamado Jorge Basadre, que ha hecho de él un interesante estudio. En estas páginas nos referimos a la confabulación de Gonzalez, la primera en ser urdida y que constituye el comienzo de la constante y sangrienta lucha que sostuvo Vivanco para mantenerse en el poder.

Desde la caída de Vidal, que era nacido en el puerto de Supe. tres concomarcanos suyos, Manuel Gonzalez, mercachifle, de 56 años: Ramón Cabero, que había sido oficial en el regimiento de Cazadores de laCEscoltade San Martín, pero que en la época que historiamos, ya de 43 años, tenía el oficio de hojalatero y Pedro Anzules, zambo libre, de la misma edad que el anterior, zapatero u hojalatero según las circunstancias, proyectaron un plan para asesinar a Vivanco.

Parece que primeramente tomó parte en sus elucubraciones un capitán del escuadrón de la Escolta llamado Manuel Jáuregui, que les ofreció facilitarles cinco individuos de tropa del mismo cuerpo, que habían sido asistentes de Vidal, para atacar al Supremo Director cuando se dirigiera al teatro, adonde iba habitualmente acompañado por sus edecanes y un piquete de doce soldados. Se dijo también que estaban complicados otros muchos oficiales, cuyos nombres no se mencionaron y a quienes Vivanco había dado de ba- 
ja, en tanto que conspiraban, recelando de su conducta, aunque sin saber con certeza sus propósitos en contra suya.

Si fué verdad que Jáuregui entró en esta conjuración, también debe haberlo sido que se desistió de seguir actuando a raíz de la deportación de Vidal. Sin embargo, las tres personas antes nombradas no abandonaron su intento de eliminar a Vivanco, pero, viéndose solos, optaron por acometer al mandatario sin extraña ayuda, aprovechando de que éste solía ir en las noches al Convento de San Francisco, acompañado solamente por dos ayudantes, para conversar con el obispo Luna Pizarro, que, según esto, podemos colegir fué uno de sus principales consejeros en su camino autocrático.

Tales visitas las supieron Gonzalez y sus amigos por un lego de ese establecimiento religioso y, decididos a llevar adelante su proyecto, se comprometieron a realizarlo en la mayor brevedad. Estos tres sujetos, de modesta posición social, actuaban por cariño a Vidal y sin que éste tuviera el menor conocimiento de lo que se proponían.

Gonzalez tenía un socio en sus actividades de pequeño comerciante, llamado Mariano Quinis, a quien puso al corriente de su idea. Quinis trató de disuadirlo de ella, pero cuando vió que seguía madurándola y podía llevarla a cabo de un momento a otro, se decidió, por temor, codicia o simpatía a Vivanco, a revelarle el plan. Comunicó personalmente lo que sabía al Director y éste comisionó a uno de su leales, el Coronel Mariano Guerola, para que descubriese toda la trama.

Guerola se puso al habla con Quinis, quien, aleccionado, le dijo a Gonzalez saber que se hallaba en Lima un emisario de Vidal y La Fuente, portador de una fuerte cantidad de dinero para fomentar una revolución y que, si estaba resuelto a hacer desaparecer a Vivanco, debía sacar provecho económico de ese acto, pidiéndole una buena suma al agente de esos generales. También le manifestó que conocía 
a esa persona y que podía presentársela. Gonzalez aceptó y Quinis lo condujo donde Guerola, que simuló llamarse $\mathrm{Ma}$ nuel Delgado y ser un enviado de los militares nombrados.

Gonzalez no tuvo inconveniente en revelarle todo su plan, así como el nombre de sus cómplices y Guerola, después de aprobar lo que le comunicaba, le manifestó que le daría ocho mil pesos, a nombre de Vidal y La Fuente, cuando se realizase el asesinato, entregándole en tanto mil adelantados, pero que era necesario para ello que trajese a los demás comprometidos. No se negó a esto Gonzalez y convinieron en que vendría con Cabero y Anzules ese mismo día, después del toque de oración.

En efecto, Gonzalez buscó a sus dos amigos y en su compañía se dirigió, a la hora fijada, en la casa de Guerola, situada en la calle de San Antonio. El Coronel se había puesto de acuerdo con el Mayor Serna, a quien colocó, convenientemente armado, en el interior del alojamiento y con el Coronel Otero, que, con algunos oficiales, debía realizar el apresamiento de los conjurados, viniendo de la calle, donde estaban apostados.

En presencia de Guerola, los complotados ratificaron sus propósitos y como les pidiese que le firmasen un recibo por los mil pesos que iba a entregarles, tampoco opusieron ninguna resistencia a tan comprometedora demanda estos hombres ignorantes. El documento expresaba que recibían de Manuel Delgado la suma de mil pesos, a cuenta de los ocho mil que deberían entregárseles por el plan propuesto de desaparecer al General Vivanco, que de su espontánea voluntad se ofrecían a efectuar en favor de los generales Vidal y La Fuente.

Una vez que firmaron, salió Guerola, con el pretexto de llamar a un criado, avisando a Otero, que entró con sus acompañantes y apresó a los conspiradores. Este hecho tuvo lugar en la noche del Io de Mayo de I843. 
De la instrucción del proceso, inmediatamente iniciado, resultó que el inventor del plan fué Gonzalez, quien complicó a los otros dos, que se le unieron de buen grado por su ilimitado afecto a su paisano Vidal. Cabero declaró no ser cierto que Jáuregui se hubiera comprometido alguna vez a coadyuvar con ellos. Fué creído su aserto y el Capitán declarado inocente. Todo hacía suponer, sin embargo, que habían militares que conocían el asunto, pero no se continuaron las investigaciones al particular.

En sus declaraciones, Gonzalez acusó a Cabero como autor del proyecto $y$, en definitiva, los tres terminaron por. confesar sus intenciones, aunque no en toda su amplitud, quedando palmariamente probada su determinación delictuosa. Además de que el recibo que habían firmado a Guerola los condenaba por si sólo El juicio fué muy breve. El Consejo de Guerra, nombrado al efecto y presidido por el General Jaramillo, sentenció a muerte a Manuel Gonzalez y. a seis años de presidio a Cabero y. Anzules.

Para condenar a Gonzalez se invocó la Ley, 2da., del Título 3r, de la Partida Gạe, del Código de Pas Siete Partidas, que se refiere a la éxeepciôn que, tratándose de la persona del soberano, se hace a la regla de derecho sostenida por ese cuerpo de leyes de que "los hombres no deben recibir pena por los malos pensamientos que tengan pero que no pongan en obra". Es decir, se aplicaba al mandatario de una democracia un fuero excepcional reservado a los monarcas de Castilla en la Edad Media.

El veredicto fué expedido el i6 de Mayo y pasó al Auditor, doctor José Blas Alzamora, quien, honradamente, opinó, con fecha I7, que Gonzalez era reo de un simple conato y que debería sufrir igual pena que la impuesta por el Consejo a los otros dos conjurados. Vivanco, sin tomar en cuenta este dictamen, aprobó la sentencia el ig de Mayo, en un decreto refrendado por el Ministro de Guerra, General Manuel de la Guarda, 
Puesto Gonzalez en capilla, expresó que tenía que ampliar sus declaraciones, en el sentido de que había estado inmiscuido en el complot un capitán, que no conocía por su nombre, pero cuyas señales particulares precisó. Colocado ante una tueda de oficiales, indicó al Capitán Gamonal como la persona a quien se refería. Este oficial era, en efecto, amigo de Cabero, frecuentaba su casa, a la que concurría para ver jugar malilla y tenía, asinismo, vinculaciones con Vi¿dal. Había ido a visitar a éste en la hacienda "Márquez", donde residió después de su alejamiento del poder, cuando ya Vivanco estaba en Lima, prestándose a traer, en una oportunidad, comunicaciones del ex-gobernante para el General Pezet y el Coronel Alvarado Ortiz. Gamonal negó categóricamente toda participación en la conjura, Cabero ratificó lo dicho por él y el Consejo lo consideró libre de toda culpabilidad.

Por tal motivo la ejecución de Gonzalez se postergó. Las tropas formaron en la Plaza de Armas en la mañana del 2I de Mayo parailopresenciar elefúsilamiento, pero éste se suspendió. Volvieron a reunirse a las cuatro de la tarde y vino otra contra orden, hasta que al día siguiente, 22 de Mayo, a las once de la mañana, Gonzalez fué pasado por las armas. El infeliz marchó amarrado desde su prisión hasta 1a plaza y se le hizo detener en todas las iglesias del tránsito, donde se doblaba y oraba por su ánima. Se escogió exprofesamente una hora de gran concurrencia para realizar este acto cruel y, según se dijo, el mismo Vivanco presenció el macabro espectáculo desde uno de los balcones del Palacio, que estaba atestado de aúlicos militares.

Gonzalez demostró gran valor. Antes de salir de la prisión manifestó que había acusado a Cabero por salvarse y que le pedía perdón por ello. No desmayó en todo el trayecto, a pesar de las impresionantes ceremonias que a su paso tenían lugar en los templos. Venía fumando tranquilamente. 
Fué sentado en un banquillo, dando la espalda al muro del $\mathrm{Pa}-$ lacio Arzobispal. Murió después de dos descargas y varios tiros sueltos. Fué una escena horrenda. La gente gritaba y se movía nerviosamente en la plaza y los portales al ver las contracciones de la víctima al recibir los disparos. E1 desorden resultó de tal proporción que salió herido por una de las balas dirigidas al ajusticiado el oficial Bonifaz.

Vivanco y su camarilla creyeron que con el aparato con que se rodeó esta ceremonia despiadada y su extremado rigor para con el culpable, daban una prueba de que constituían un gobierno enérgico. Fué todo lo contrario. Se comentaba que Gonzalez había sido fusilado porque se trataba de un pobre mercader ambulante, pero que detrás de él actuaron otras personas, como lo demostraba el hecho de haber aparecido complicados en el proceso varios oficiales del ejército y que el Supremo Director y el Consejo de Guerra admitieron la inocencia de todos ellos por no atreverse a herir a sujetos altamente colocados y, sobre todo, a los institutos armados. En cambio, la capital y el país entero quedaron con una impresion ingratacante ceste castigosexcesivo, revelador del carácter cruted y tiránicoide Vivanco,

De estos últimos acontecimientos se ocupa Max Radiguet en su libro "Souvenirs d'un voyage par la Amérique du Sud" y nos permiten constatar, una vez más, la veracidad de este viajero francés.

La escena del fusilamiento que él nos describe minuciosamente, coincide con el suelto de "El Comercio" del 22 de Mayo de I843, en que se hace referencia a lo ocurrido en la mañana de ese día con motivo de este cruento suceso.

Verdad es que Radiguet, más descriptivo que narrador, olvida consignar el nombre del sentenciado y la fecha de la 
ejecución, aunque es fácil identificar el hecho por varios detalles inequívocos. A este respecto, a pesar de que este autor hace en su mencionada obra una exposición de la existencia republicana del Perú, la frecuente omisión de datos cronológicos y su manifiesta falta de interés para concatenar los acontecimientos, nos revelan que fué más un observador geográfico y costumbrista que un curioso de lo histórico.

\section{Teodosio Cabada.}

